\title{
Introducing The Computer Journal
}

The international journal of information technology and computer applications

Editor-in-Chief P Hammersley,Middlesex Polytechnic, The Burroughs, Hendon, London NW4 4BT, UK

\section{Coverage}

The Computer Journal is one of the world's most eminent periodicals in the field of information technology and computer applications. Its coverage is unmatched by any other computing periodical. It includes advanced programming, computer science theory, databases, hardware and logic design and business applications. It also covers the newer disciplines such as parallel computing, object-oriented programming, logic programming and electronic publishing. Papers are always in the mainstream of new developments; their results are significant and far reaching; above all they are readable.

\section{Type of Articles Published}

The Computer Journal publishes original research papers, practical accounts of the latest developments and their likely impact, shorter communications, correspondence about recently published articles, and review articles.

The quality and scope of The Computer Journal can be seen from just a selection of recent and forthcoming articles. Send for a free sample copy and see for yourself!

\section{Subscription information}

The Computer Journal (ISSN0010-4620), Volume 34: February, April, June, August, October and December 1991. f174 for UK subscribers, $£ 185$ for subscribers elsewhere.

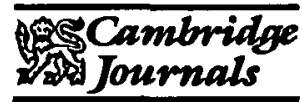

Cambridge University Press

The Edinburgh Building, Cambridge CB2 2RU, England 40 West 20th St, New York, NY 10011-4211, USA 


\section{A NEW journal in the applications of categorical, algebraic and geometric methods in Computer Science Mathematical Structures in Computer Science}

\section{Why a new journal?}

Mathematical Structures in Computer Science (MSCS) is a new journal of theoretical computer science which focuses on the application of ideas from the structural side of mathematics and mathematical logic to computer science. The journal aims to bridge the gap between theoretical contributions and software design, publishing original papers or broad surveys with original perspectives in all areas of computing, provided that ideas or results from algebra, geometry or category theory form a basis for the work. MSCS is distinct from existing titles in that it specialises in the art of applying mathematics of genuine interest and general applicability to computer science; its objective is to promote the useful application of high level mathematics to language design and software implementation. The journal will increase the circulation of new results in this fast growing area.

\section{Editor-in-Chief}

\section{$G$ Longo}

Ecole Normale Supérieure, 45 rue d'Ulm, 75230 Paris (email:

longo@earn.frulm63)

\section{Associate Editors}

\section{PLCurien}

Laboratoire d'Informatique, Ecole Normale Supérieure, Paris

A M Pitts

Computer Laboratory, University of Cambridge

\section{Forthcoming articles}

From Petri Nets to Linear Logic Narcisio Martr-Oliet \& Jose Mesecuer Impredicative Calculi of Dependent Types

THOMAS StREICHER

Operations on Records Luca CardeLI \& John C Mitchell

Predicate Transformer Semantics ERNIE MANES

Declarative Continuations: An Investigation of Duality in Programming ANDRZEJ FIUNSKI

A Category-theoretic Account of Program Modules EUCENIO MOCOI

What is Functional Programming? RFCWALTERS

\section{Subscription information}

Mathematical Structures in Computer Science, Vol 1: March, July and November 1991: $£ 75 / \$ 135$. Delivery by airmail $£ 9.50$ peryear extra (dollarprice includes airfreight to New York). ISSN $0960-1295$

Send your order to Journals Publicity Department, Cambridge University Press, FREEPOST: The Edinburgh Building, Shaftesbury Road, Cambridge CB2 18R, England TEL: (0223) 325806, FAX (0223) 315052

- no postage stampnecessary if posted in UK In US \& Canada, write to: Cambridge University Press, 40 West 20 th Street, New York, NY 100114211, USA 


\section{Cambridge}

\section{Models of Brain Function \\ RODNEY M. J. COTTERILL}

Recent progress has been such that it now seems realistic to look towards an explanation of mind in terms of the brain's anatomy and physiology. This book presents a comprehensive overview of the current state of brain modelling, containing contributions from many leading researchers in this field. It will be of interest not only to researchers in the fields of brain science and neurobiology, but to psychologists and those involved in the study of artificial intelligence.

f42.50 net HB 0521385032574 pp. 1990

\section{Foundations of Artificial Intelligence}

A Sourcebook

Edited by DEREK PARTRIDGE and YORICK WILKS

This outstanding collection is designed to address the fundamental issues of principles underlying the task of Artificial Intelligence. The editors have selected not only papers now recognised as classics but also many specially commissioned papers which together examine the methodological and theoretical foundations of the discipline from a variety of perspectives. $£ 45.00$ net HB $0521351030 \quad 512$ pp. 1990 $£ 15.00$ net PB 0521359449

\section{Updating Logical Databases \\ MARIANNE WINSLETT}

This book tackles the problems of update algorithms for databases. The author has produced a formal method for specifying the desired change intentionally, using a 'formulabased' approach to updating needs rather than a 'model-based' technique. The complexity of the algorithms, choice of semantics and a means of enforcing integrity constraints are also discussed. $£ 20.00$ net HB $0521373719 \quad 224$ pp. 1990 Cambridge Tracts in Theoretical Computer Science 9

\section{Modeling Brain Function}

The World of Attractor Neural Networks DANIEL J. AMIT

This book introduces the techniques brought from physics to the study of neural networks and the insights they have stimulated. It is written at a level accessible to the wide range of researchers working on these problems statistical physicists, computer scientists and cognitive psychologists. The author has been careful to give a coherent and non-technical presentation of all the basic ideas.

f27.50 net HB 0521361001528 pp. 1989

\section{Now in paperback}

\section{Formal Methods in Artificial Intelligence}

\section{ALLAN RAMSAY}

Artificial Intelligence has recently turned to formal logic in the search for powerful knowledge representation languages. Covering a wide range of topics, this book is aimed at all researchers in artificial intelligence.

c.f13.95 net PB 0521424216296 pp. 1991 Cambridge Tracts in Theoretical Computer Science 6

\section{Formal Semantics and Pragmatics for Natural Language Querying \\ JAMES CLIFFORD}

This book discusses the connection between the areas of semantics, namely the semantics of databases and the semantics of natural language, and links them via a common view of the semantics of time. A formal model for the interpretation of questions is presented in this work which will form the basis for much further research.

f19.50 net HB 0521354331208 pp. 1990 Cambridge Tracts in Theoretical Computer Science 8

For further information please contact Susan Chadwick at the address below

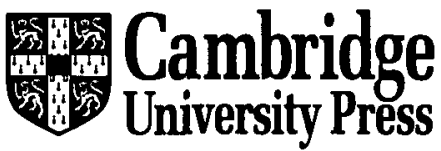

The Edinburgh Building, Cambridge CB2 2RU, UK. 


\section{Cambridge}

\section{A Theory of Computer Semiotics}

Semiotic Approaches to Construction and Assessment of Computer Systems

\section{P. B. ANDERSEN}

Computer semiotics studies the special nature of computer-based signs and how they function in use. This book is based on ten years research on computer usage in work situations and it presents a novel approach to the subject, that is both theoretically systematic and practical.

f30.00 net HB $0521393361 \quad 424$ pp. 1991 Cambridge Series on Human-Computer Interaction 3

\section{Hypertext Research Practice \\ C. MCKNIGHT, A. DILLON and J. RICHARDSON}

Hypertext is the term coined for the storage of electronic data, whether it be textual or graphic, in such a way that the whole file becomes an electronic 'concordance'. Rather than simply summarise everything that has gone before, it aims to provide a position statement from which further work may be suggested.

f16.95 net HB $052137488 \times \quad 176$ pp. 1991 Cambridge Series on Electronic Publishing 4

\section{Logic and Information KEITH DEVLIN}

A noted expositor and regular Guardian columnist provides a ground-breaking discussion on the nature of logic. He develops his theory in general and intuitive terms and explores its relevance to a variety of concerns such as artificial intelligence, cognition, natural language and communication. Readers whose imaginations have been stimulated by books such as The Liar and The Emperor's New Mind will find this unique book equally thoughtprovoking.

c. 115.00 net HB $0521410304 \quad$ c.400 pp.

Forthcoming May 1991

\section{Human Factors for Informatics Usability Edited by BRIAN SHACKEL and SIMON RICHARDSON}

Human factors is one of the critical issues in information technology, as industry realises the need to change from technologyorientated goals to meet the demands of computer users. This book has been developed from lectures to provide a comprehensive introduction and a thorough guide to what is known about informatics usability, and how it can solve practical problems.

$£ 35.00$ net HB $0521365708 \quad 452$ pp. 1991

\section{Research and Development in Expert Systems VII \\ Proceedings of 10th Annual Technical Conference of the BCS Specialist Group, September 1990}

Edited by T. R. ADDIS and R. M. MUIR

Three issues are examined in this volume: cybernetics, databases and programming languages. These issues reflect the ubiquity of expert systems, showing how the methods are helping to expand other areas of technology. It will be essential reading for those who wish to keep up to date with developments in this field.

$£ 25.00$ net HB $0521404037 \quad 327$ pp. 1990 British Computer Society Workshop Series

\section{Computability and Logic}

Third Edition

GEORGE S. BOOLOS and

RICHARD C. JEFFREY

A text for second course in logic for graduate and advanced undergraduate students. This third edition has been corrected and contains thoroughly revised versions of the chapters on Ramsey and provability, with new exercises provided for three other chapters.

f37.50 net HB $052138026 \times 285 \mathrm{pp}$. E13.95 net PB 0521389232

For further information please contact Susan Chadwick at the address below

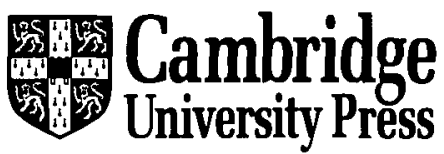

The Edinburgh Building, Cambridge CB2 2RU, UK. 


\section{The knowledge engineering review}

\section{Notes for Contributors}

Contributions for publication should be addressed to Dr John Fox, Editor, The Knowledge Engineering Review, Biomedical Computing Unit, PO Box 123, Lincoln's Inn Fields, London WC2A 3PX, England, Dr Peter Jackson, North American Editor, McDonnell-Douglas Research Lab, Artificial Intelligence Group, PO Box 516, St Louis, MO 63166, USA, or may be submitted through a member of the Editorial Advisory Board (addresses inside front cover). Submission implies that the manuscript has not been published previously nor currently submitted for publication elsewhere.

All contributions, whether articles, correspondence or reviews, must be sent in triplicate and typed on one side of the paper, with wide margins and double-line spacing throughout. Any minor corrections should be made neatly in the typescript, leaving the margins clear. The author is invited to nominate up to five possible referees, who will not necessarily be used.

Articles must be accompanied by a brief, informative rather than indicative, abstract. Headings should be set out clearly but not underlined. Primary headings should be in lower case, at margin, with arabic numeral; subheadings should be numbered 2.a., 2.b., etc., and tertiary headings, 2.a.1., 2.a.2. No cross-references should be given by page number, but 'above' and 'below' should be used with the section specified, e.g. Section 2.a.2. The SI system of units should be used. The author should mark in the margin of the manuscript where figures and tables may be inserted. References to points in larger works should, where possible, quote the page reference, e.g. Ager, 1981, p. 102.

Tables should be typed with double-line spacing on sheets separate from the running text. Each table must have a caption that will make the data in the table intelligible without reference to the text.

Illustrations should be drafted for reproduction as full page $(148 \mathrm{~mm})$ width. Originals should normally be drawn at twice final area and must be sent in a flat package; larger drawings may delay publication. Lettering should be of a size so that when reduced the smallest lower-case letters will not be less than about $1 \mathrm{~mm}$. Avoid gross disparities in lettering size on a drawing. Duplicates of illustrations should be sent, and may be prints or, preferably, photocopies reduced to final size. Illustrations in the text, both line drawings and photographs for halftone reproductions, will be referred to as figures (Fig. 2, 2a, etc.). Folding plates will not be accepted. Figures composed of photographs should be glossy prints presented at publication scale. Figure captions must be typed with double-line spacing on sheets separate from the running text.

The accuracy of references is the responsibility of authors. References must be double-spaced and spelt out in full, e.g.

Gale, W A, ed 1986. Artificial Intelligence and statistics, Reading, Massachusetts: Addison-Wesley

Pearl, J 1984. Heuristics. Intelligent search strategies for problem solving, Reading, Massachusetts: AddisonWesley

Tie-Cheng Wang and Bledsoe, W W, 1987. "Hierarchical deduction" Journal of Automated Reasoning 3 (1) ppl-34.

Pau, L F, 1986. "Survey of expert systems for fault detection, test generation and maintenance" Expert Systems, $3(2)$ pp 100-111.

Twenty Five offprints of each paper will be provided free of charge. Additional offprints may be purchased according to a set scale of charges if ordered when the proofs are returned. 


\section{The knowledge}

engineering

\section{review}

VOLUME 6 NUMBER 1 MARCH 1991

\section{Contents}

Fxplaining reasoning: an overview of explanation in knowledge-based systems

RICIIARI) W. SOLIIIWICK

A review and synthesis of user modelling in intelligent systems

A IRI J. KOK

Book revicus

From the journals

\section{CAMBRIDGE UNIVERSITY PRESS}

Published by the Press Syndicate of the University of Cambridge The Pitt Building, Trumpington Street, Cambridge CB2 1RP

40 West 20th Street, New York, NY 10011-4211, USA

10 Stamford Road, Oakleigh, Melbourne 3166, Australia

Typeset by Paston Press, Loddon

Printed in Great Britain by Henry Ling Ltd, Dorchester 